\title{
Yabancılara Türkçe Öğretiminde Kullanılan Yeni Hitit 3 ve İstanbul C1+ Ders Kitaplarındaki Metinlerin Okunabilirlik Düzeylerinin Karşılaştırılması*
}

\section{Comparison of Readability Degree of Texts in Yeni Hitit 3 and İstanbul C1+ Text Books Which are Used in Teaching Turkish to Foreigners}

\begin{abstract}
Nurşat BİÇER**, Yakup ALAN***
Öz: $\mathrm{Bu}$ araştırmanın amacı; yabancılara Türkçe öğretimi için hazırlanan Yeni Hitit 3 ve İstanbul C1+ kitabındaki metinlerin okunabilirlik düzeylerini belirlemektir. Çalışmada nitel araştırma yöntemlerinden doküman incelemesi kullanılmıştır. Araştırmacılar tarafından ders kitaplarındaki metinlerin hece, sözcük ve cümle uzunlukları hesaplanmıştır. Elde edilen veriler Ateşman'ın (1997) Türkçeye uyarladığı Flesch formülü kullanılarak analiz edilmiş ve metinlerin okunabilirlik puanları belirlenmiştir. Daha sonra kitaplarda yer alan metinlerin kolaydan zora doğru sıralaması yapılarak metinler öğrenci düzeyine uygunluğu açısından karşılaştırılmıştır. İki kitap arasında istatistiksel olarak anlamlı farklılık olup olmadığını belirlemek için t-testi yapılmıştır. Araştırma sonucunda iki kitap arasında sözcük uzunluğu, cümle uzunluğu ve okunabilirlik puanları arasında anlamlı farklılık olduğu görülmüştür. Araştırmada elde edilen sonuçlara göre Yeni Hitit 3 ders kitabının İstanbul $\mathrm{C} 1+$ ders kitabına göre daha zor düzeyde metinlerden oluştuğu saptanmıştır. Araştırmanın sonuçlarından hareketle bu alanda ders kitabı hazırlayanlara yönelik önerilerde bulunulmuştur.
\end{abstract}

Anahtar Kelimeler: Okunabilirlik, yabancılara Türkçe öğretimi, yeni Hitit, ders kitabı, İstanbul C1+

Abstract: In this study, it is aimed to determine readability degree of texts which are in Yeni Hitit 3 Yeni Hitit 3 and İstanbul $\mathrm{C} 1+$ used by many language centers for teaching Turkish to foreigners. Document analysis from quality research methods is used in this study. Syllable, word and sentence lengths are calculated by selecting texts in the text books by researches. Digital data is analyzed by using Flesch formula which was adapted to Turkish by Ateşman (1997) and readability scores of texts are determined. In the study, the texts in the books were ordered from the easy to the hard and the texts were compared in terms of their suitability to the student level. Independent sampling t-test is used to determine if there is difference between two books. As a result of the research, it was seen that there was a significant difference between word length, sentence length and readability scores between two books. According to this, it can be said that the Yeni Hitit 3 course book is composed of texts more difficult than the Istanbul $\mathrm{C} 1+$ course book. It is expected that this study will give an idea about how the books which are widely used in teaching Turkish to foreigners should be in terms of the readability level.

Keywords: Readability, teaching Turkish to foreigners, new Hitit, course book, Istanbul C1+

\section{Giriş}

Eğitimin her kademesinde olduğu gibi yabancılara Türkçe öğretiminde de ders kitapları en çok kullanılan önemli materyallerden biridir. Türkçenin yabancı dil olarak öğretimi için hazırlanan kitaplarda okuma, yazma, dinleme ve konuşma becerileri ve dil bilgisi öğrenme alanı dikkate alınarak yabancıların bu becerileri geliştirmesi amaçlanmıştır. Yabancı dil olarak Türkçe öğretimi için hazırlanan ders kitaplarında yukarıda sayılan becerilerin geliştirilmesi için

\footnotetext{
*Bu makale, 27-28 Nisan 2017 tarihleri arasında Bursa'da düzenlenen "Uluslararası Yabancı Dil Öğretimi ve Yabancı Dil Olarak Türkçe Öğretimi Sempozyumu”nda sunulan sözlü bildiriden üretilmiştir.

**Yrd. Doç. Dr., Kilis 7 Aralık Üniversitesi, Muallim Rıfat Eğitim Fakültesi, Kilis-Türkiye, e-posta: nursatbicer@gmail.com

***Öğr. Gör., Kilis 7 Aralık Üniversitesi, Muallim Rıfat Eğitim Fakültesi, Kilis-Türkiye, e-posta: alanyakup@gmail.com
} 
metinlerden sıkça yararlanılmakta ve metinler önemli bir öğrenme aracı olarak kullanılmaktadır. $\mathrm{Bu}$ nedenle temel materyal olma özelliğine sahip olan ders kitaplarında yer alan metinlerin hedef ve içinde bulunulan dil seviyesine (A1-A2-B1-B2-C1) uygunluğu oldukça önemlidir. Bu bağlamda düzeye uygun metinlerle okuma çalışmalarından fayda sağlanabilecek ve yabancılara Türkçe öğretiminin hedeflerine ulaşılacaktır.

Ders kitaplarına metin seçerken metinlerin hedef kitleye uygunluğunu anlamanın çeşitli yolları vardır ve bu yollardan biri de metinlerin okunabilirlik düzeylerini belirlemektir. Okunabilirlik kavramı genellikle bir metnin okunma güçlügünün birtakım matematiksel formüller aracılı̆̆ıyla hesaplanması anlamında kullanılmaktadır (Ülper, 2010). Ateşman'a (1997) göre ise okunabilirlik, metinlerin okuyan tarafından kolay ya da güç anlaşılır olmasıdır. Okunabilirlik çalışmalarının amacı metinde anlaşılabilir bir dil kullanmayı sağlamaktır (Chall, 1988). Metnin dilinin anlaşılabilir olması metni okumaya devam etmeyi sağlamada ve metinle okur arasında ilişki kurmada bir başlangıç noktası olarak kabul edilebilir.

Metnin okunabilirlik düzeyinin öğrenci düzeyine uygun olmamas1 durumunda öğretimde olumsuz durumlar yaşanabilir. Metnin güç olması öğrencinin okuma yeteneğini zorlamakta; kolay olması da ilgi uyandırmamaktadır. Bu nedenle öğrencilere zorluk derecelerine göre okuma metni seçilmelidir (Güneş, 2000, s. 235). Çünkü öğrenciler, öğretimsel metinlerin zorluk düzeyleri, kendilerinin okuma seviyeleri ile aynı olduğu zaman en uygun öğrenmeyi gerçekleştirmektedirler (Zakaluk ve Samuels, 1988, aktaran Solmaz, 2009, s. 14). Bu nedenlerle uygun öğrenmenin gerçekleşebilmesi ve doğru metinlerin seçilebilmesi için metinlerin okunabilirlik düzeylerini tanımlamaya ve sınıflamaya yönelik çalışmalar yapılmış ve farklı yöntemler denenmiştir. Metinlerin okunabilirlik düzeylerinin tanımlanması ve sınıflandırılmasına yönelik alanyazınında genel kabul görmüş üç yaklaşım vardır. Bunlar; uzman görüşü, çıkartmalı okunabilirlik işlemi ve okunabilirlik formülüdür (Klare, 1963, Aktaran Çetinkaya ve Uzun, 2010, s. 142).

Okunabilirlik formülleri, metnin zorluk seviyesinin kelime uzunluğu ve cümle uzunluğu gibi metnin sayılabilir öğelerinin, sayısal verilere dayanarak tahmin etmeye yarayan araçlardır (Chatman ve Goetz, 1985, s. 150, aktaran Hizarc1, 2009, s. 50). Bu yüzden okunabilirlik formülleri ders kitaplarına uygun metin seçme, bireye veya gruba uygun kitap belirleme amaciyla kullanılmaya uygundur (Temur, 2003). Formüllerin kullanımının kolay olması ve nesnel sonuçlar vermesi sayesinde formüller sık kullanılan araçlar olmuşlardır. Kesin bir ölçüt olmamakla birlikte formüller metnin güçlüğü hakkında fikir verir.

Bir metnin okuyucu tarafından kolay algılanması metni anlamaya yönelik sürecin ilk basmağı olarak düşünülebilir. Ancak metinle ilgili sayısal verilerin metnin anlaşılabilir olmasını garantileyeceği söylenemez. Okunabilirlik ve anlaşılabilirlik genellikle farklı kavramlar olarak görülmektedir. Anlaşılabilirlik, metne ait niceliksel özelliklerin yanı sıra birtakım niteliksel özelliklere de bağımlıdır (Ateşman, 1997). Buna göre anlaşılabilirlik metinde hangi konudan söz edildiğine, düşüncenin hangi sırayla ve nasıl aktarıldığına ve okuyanın o konuda bilgisinin olup olmadığına göre değişmektedir (Ateşman, 1997). Metnin nitel özellikleri ve okuyucunun özellikleri anlama sürecinin tamamlayıcıları olacaktır. Dolayısıyla bir metnin okunabilir olduğunu söylemek veya o metnin hangi sınıfa hitap ettiğini adreslemek metinlerin anlaşılabilirliği hakkında az da olsa bilgi verebilmektedir." (Bezirci ve Yılmaz, 2010, s. 60).

Türkiye'de okunabilirlik kavramıyla ilgili çalışmaların 90'larda başladığı görülmektedir. Bu alanda Türkçe metinlerin güçlük düzeylerini tanımlamak ve sınıflamak amacıyla ilk çalışma Ateşman (1997) tarafından yapılmıştır. Yine bir diğer önemli çalışmayı ise doktora tezi olarak Çetinkaya (2010) hazırlamıştır. Bu çalışmada Türkçe metinlerin okunabilirlik düzeylerini tanımlama ve sınıflamaya yönelik formül geliştirilmiştir.

Alanyazında metinlerin okunabilirliğiyle ilgili çokça çalışma olmasına rağmen yabancılara Türkçe öğretimi alanında bu çalışmalar yetersizdir. Bu alanda Yılmaz ve Temiz (2014) Hitit serisindeki metinleri inceleyen bir çalışma yapmıştır. Bu çalışmada ise Hitit 3 ile İstanbul $\mathrm{C} 1+$ kitapları okunabilirlik açısından karşılaştırılmıştır. Yabancı dil olarak Türkçe öğretiminde yaygın bir şekilde kullanılan bu iki serinin kitaplarının okunabilirlik açısından karşılaştırılmasının alana önemli katkılar sağlayacağı düşünülmektedir. 
$\mathrm{Bu}$ araştırmada; yabancılara Türkçe öğretimi için hazırlanan Yeni Hitit 3 ve İstanbul $\mathrm{C} 1+$ kitabındaki metinlerin okunabilirlik düzeylerini belirlemek amaçlanmıştır. Belirlenen amaç çerçevesinde aşağıdaki araştırma sorularına yanıt aranmıştır:

- Yeni Hitit 3 kitabındaki metinlerin okunabilirlik düzeyleri nasıldır?

- İstanbul $\mathrm{C} 1+$ kitabındaki metinlerin okunabilirlik düzeyleri nasıldır?

- Yeni Hitit 3 ile İstanbul $\mathrm{C} 1+$ kitaplarındaki metinlerin okunabilirlik puanları arasında anlamlı bir farklılık var mıdır?

\section{Yöntem}

\section{Araştırma Modeli}

Yabancı dil olarak Türkçe öğretiminde kullanılan ders kitaplarındaki metinlerin okunabilirlik açısından Karşılaştırılmasını amaçlayan bu çalışmada doküman incelemesi modeli kullanılmıştır. Doküman incelemesi, araştırılması hedeflenen olgu veya olaylar hakkında bilgi içeren yazılı materyallerin analizini kapsar (Yıldırım ve Şimşek, 2008, s. 187). Bu yöntemle metinlerin var olan durumu betimlenmiştir.

\section{İncelenen Dokümanlar}

Çalışmada yabancılara Türkçe ögretiminde kullanılan Yeni Hitit 3 ve İstanbul $\mathrm{C} 1+$ ders kitapları seçilmiştir. Bu kitapların yaygın bir şekilde kullanılması ve ileri düzey Türkçe için hazırlanmış olmaları bu kitapların seçilmesindeki en önemli etkendir. Yeni Hitit 3'e ait veriler Yılmaz ve Temiz (2014) tarafından yapılan çalışmadan alınmış, İstanbul C1+ kitabının hesaplamaları ise araştırmacılar tarafından yapılmıştır. Yeni Hitit 3 kitabında 38; İstanbul C1+ kitabında ise 36 metin okunabilirlik açısından incelenmiştir.

\section{Verilerin Toplanması ve Analizi}

Ders kitaplarındaki düzyazıya dayalı metinler araştırmacılar tarafından belirlenerek hece, sözcük ve cümle uzunlukları hesaplanmıştır. Heceler Türkçenin hece belirleme metoduna göre bölümlenmiştir. Sözcük sayısı belirlenirken boşlukla aralanmıș sayılar, semboller ve birleștirme çizgisiyle ayrılmış sözcükler ve kısaltmalar sözcük olarak kabul edilmiştir. Cümlelerin sayısı ise noktalama işaretleriyle ayrılma durumlarına göre belirlenmiştir. Belirlenen veriler SPPS 17.0 programıla analize tabi tutulmuştur. Analiz yapılırken iki kitap arasında farklılık olup olmadığını belirlemek için bağımsız örneklemler t-testi kullanılmıştır.

Belirlenen sayısal veriler Ateşman'ın (1997) Türkçeye uyarladığı Flesch formülü kullanılarak analiz edilmiş ve metinlerin okunabilirlik puanları belirlenmiştir.

Okunabilirlik Say1s1 $=198,825-(40,175 . x 1)-(2,610 . x 2)$

$\mathrm{x} 1=$ Hece olarak ortalama kelime uzunluğu

x2=Kelime olarak ortalama cümle uzunluğu

Tablo 1

Okunabilirlik Sayısı ve Düzeyi Aralıkları

\begin{tabular}{cc}
\hline Okunabilirlik Düzeyi & Okunabilirlik Sayıs1 \\
\hline Çok Kolay & $90-100$ \\
Kolay & $70-89$ \\
Orta Güçlükte & $50-69$ \\
Zor & $30-49$ \\
Çok Zor & $1-29$ \\
\hline
\end{tabular}

\section{Bulgular}

Yeni Hitit 3 ders kitabındaki metinlerin okunabilirlik düzeyleri hesaplanmış ve sonuçlara ilişkin bilgiler Tablo 2'de gösterilmiştir. 
Tablo 2

Yeni Hitit 3 Ders Kitabındaki Metinlerin Okunabilirlik Durumları

\begin{tabular}{|c|c|c|c|c|c|c|c|c|}
\hline : & Metnin Ad1 & $\begin{array}{l}\text { Top. } \\
\text { Hece } \\
\text { Say1s1 }\end{array}$ & $\begin{array}{l}\text { Top. } \\
\text { Kelime } \\
\text { Say1s1 }\end{array}$ & $\begin{array}{l}\text { Top. } \\
\text { Cüml } \\
\text { e } \\
\text { Sayis } \\
1\end{array}$ & $\begin{array}{l}\text { Ortalama } \\
\text { Kelime } \\
\text { Uzunluğu }\end{array}$ & $\begin{array}{l}\text { Ortalama } \\
\text { Cümle } \\
\text { Uzunluğu }\end{array}$ & $\begin{array}{l}\text { Okunabilirlik } \\
\text { Puanı }\end{array}$ & $\begin{array}{l}\text { Okunabilir } \\
\text { lik } \\
\text { Düzeyi }\end{array}$ \\
\hline 1 & Şimdiki Çocuklar Harika (s. & 247 & 104 & 12 & 2,375 & 8,666667 & 80,78938 & Kolay \\
\hline 1 & Beyaz Gemi (s. 14) & 301 & 111 & 7 & 2,711712 & 15,85714 & 48,49484 & Zor \\
\hline 2 & Aşk mı İhanet mi? (s. 22) & & 102 & 9 & 2,598039 & 11,33333 & 64,86877 & Orta \\
\hline 2 & Büyümek mi Yaşlanmak mı? & 295 & 111 & 9 & 2,657658 & 12,33333 & 59,8636 & Orta \\
\hline 2 & İhtiyar Delikanlı (s. 28) & 287 & 114 & 10 & 2,517544 & 11,4 & 67,92868 & Orta \\
\hline 3 & Korkudan Fobiye (s. 32) & 301 & 115 & 7 & 2,617391 & 16,42857 & 50,79273 & Orta \\
\hline 3 & Aşk mı Tutku mu? (s. 34) & 293 & 109 & 12 & 2,688073 & 9,083333 & 67,12415 & Orta \\
\hline 3 & Obsesif Aşklar (s. 40) & 278 & 100 & 9 & 2,78 & 11,11111 & 58,1385 & Orta \\
\hline 4 & İskoçya Denince Akla... (s. 52) & 300 & 112 & 7 & 2,678571 & 16 & 49,45339 & Zor \\
\hline 5 & Ah Bir Zengin Olsam (s. 57) & 252 & 101 & 8 & 2,49505 & 12,625 & 65,63514 & Orta \\
\hline 5 & Lüksün Sınırı Yok (s. 58) & 240 & 111 & 7 & 2,162162 & 15,85714 & 70,57299 & Kolay \\
\hline 5 & Parayla Mutluluk Olur mu? (s. & 321 & 110 & 6 & 2,918182 & 18,33333 & 33,73705 & Zor \\
\hline 6 & İkinci Dilim Türkçe (s. 68) & 298 & 100 & 7 & 2,98 & 14,28571 & 41,81779 & Zor \\
\hline 6 & Bedenin Söyledikleri (s. 72) & 370 & 118 & 3 & 3,135593 & 39,33333 & $-29,8075$ & Çok Zor \\
\hline 6 & $\begin{array}{l}\text { Yazalım mı? Konuşalım mı? } \\
\text { (s. 74) }\end{array}$ & 272 & 103 & 6 & 2,640777 & 17,16667 & 47,9268 & Zor \\
\hline 6 & $\begin{array}{l}\text { Ben de Amerikan } \\
\text { Delikanlısıyım (s. 77) }\end{array}$ & 289 & 102 & 19 & 2,833333 & 5,368421 & 70,98425 & Kolay \\
\hline 7 & Mizahın Gücü (s. 80) & 312 & 102 & 7 & 3,058824 & 14,57143 & 37,90534 & Zor \\
\hline 7 & Yabancı Diller (s. 84) & 320 & 108 & 8 & 2,962963 & 13,5 & 44,55296 & Zor \\
\hline 7 & Sessiz ve Derinden (s. 86) & 380 & 120 & 8 & 3,166667 & 15 & 32,45417 & Zor \\
\hline 7 & En Miskin, En Komik Kedi (s. & 334 & 108 & 8 & 3,092593 & 13,5 & 39,34509 & Zor \\
\hline 8 & Müziğin Matematiği (s. 91) & 295 & 102 & 9 & 2,892157 & 11,33333 & 53,0526 & Orta \\
\hline 8 & Müzikle Tedavi (s. 96) & 295 & 103 & 8 & 2,864078 & 12,875 & 50,15693 & Orta \\
\hline 8 & Notalarda İsyan (s. 98) & 301 & 103 & 5 & 2,92233 & 20,6 & 27,65439 & Çok Zor \\
\hline 9 & $\begin{array}{l}\text { Eski Türk Evlerinin Mimarisi } \\
\text { (s. 104) }\end{array}$ & 329 & 108 & 6 & 3,046296 & 18 & 29,46005 & Çok Zor \\
\hline 9 & Trev & 311 & 111 & 6 & 1802 & 18,5 & 7761 & Zor \\
\hline 9 & Assos (s. 110) & 290 & 107 & 6 & 2,685185 & 18 & 43,96769 & Zor \\
\hline 9 & $\begin{array}{l}\text { Mimaride Çevreci Tasarımlar } \\
\text { (s. 112) }\end{array}$ & 305 & 101 & 7 & 3,019802 & 14,42857 & 39,84588 & Zor \\
\hline 10 & $\begin{array}{l}\text { Televizyona Bağlı Hayatlar (s. } \\
\text { 116) }\end{array}$ & 312 & 102 & 7 & 3,058824 & 14,57143 & 37,90534 & Zor \\
\hline 10 & $\begin{array}{l}\text { Iss1z Bir Adaya Düşseniz (s. } \\
118 \text { ) }\end{array}$ & 284 & 103 & 5 & 2,757282 & 20,6 & 34,28521 & Zor \\
\hline 10 & Hayata Kisa Bir Mola (s. 121) & 296 & 101 & 5 & 2,930693 & 20,2 & 28,36241 & Çok Zor \\
\hline 10 & $\begin{array}{l}\text { Televizyonda Yarış Var (s. } \\
\text { 124) }\end{array}$ & 342 & 124 & 4 & 2,758065 & 31 & 7,109758 & Çok Zor \\
\hline 11 & $\begin{array}{l}\text { Kadın ve Erkek Beyni Farklı } \\
\text { mı? (s. 129) }\end{array}$ & 274 & 100 & 7 & 2,74 & 14,28571 & 51,45979 & $\begin{array}{c}\text { Orta } \\
\text { Güçlükte }\end{array}$ \\
\hline 11 & Zeka Bir İşe Yarar mı? (s. 132) & 263 & 104 & 14 & 2,528846 & 7,428571 & 77,84003 & Kolay \\
\hline 11 & Çare Sizsiniz (s. 134) & 311 & 101 & 5 & 3,079208 & 20,2 & 22,39582 & Çok zor \\
\hline 11 & $\begin{array}{l}\text { Beyin Hakkındaki Gerçekler } \\
\text { (s. 137) }\end{array}$ & 302 & 101 & 7 & 2,990099 & 14,42857 & 41,0392 & Zor \\
\hline 12 & Paralel Evrenler (s. 140) & 310 & 100 & 7 & 3,1 & 14,28571 & 36,99679 & Zor \\
\hline 12 & Uzaya Gitmeden Önce & 360 & 124 & 5 & 2,903226 & 24,8 & 17,4599 & Çok zor \\
\hline 12 & Astrolojinin Doğuşu (s. 148) & 320 & 105 & 7 & 3,047619 & 15 & 37,2369 & Zor \\
\hline
\end{tabular}


Hitit 3 Ders Kitabı incelendiğinde, kitabın 12 bölümden ve 38 metinden oluștuğu görülmektedir. Metinler ortalama uzunlukları 2,35 ile 3,16 arasında değişen sözcükten oluşmaktadır. Türkçenin ortalama kelime uzunluğu dikkate alındığında 6 metnin ortalamanın altında olduğu 32 metnin ise ortalamanın üstünde olduğu görülmektedir. Yeni Hitit 3 kitabında yer alan metinlerin ortalama cümle uzunlukları 5,36 ile 39,33 arasında değişmektedir. Türkçenin ortalama cümle uzunluğu Ateşman'a (1997) göre 9-10 sözcükten, Bezirci ve Yılmaz'a (2010) göre ise 10-11 sözcükten oluşmaktadır. Ateşman'ın (1997) ortalama cümle uzunluğu dikkate alındığında 3 metin ortalamanın altında 35 metin ise ortalamanın üstündedir.

80,78 ile -29,80 arasında değişen okunabilirlik düzeyine sahip metinler incelendiğinde ise çoğunun zorluk düzeyi açısından zor sınıfında yer aldığı görülmektedir. Buna göre metinlerin 7 tanesi çok zor, 17 tanesi zor, 10 tanesi orta güçlükte, 4 tanesi ise kolay düzeydedir. Kitabın en zor metni -29,80 okunabilirlik düzeyine sahip Bedenin Söyledikleri, en kolay metni ise 80,78 zorluk düzeyi ile Şimdiki Çocuklar Harika isimli metinlerdir. Kitapta yer alan metinler zorluk düzeyleri açısından öğrenci seviyesine uygundur; ancak eserde yer alan Bedenin Söyledikleri isimli metin seviyenin oldukça üstündedir. Kitaptaki metinler zorluk seviyelerine göre sıralanmamıştır. Metinler kolaylık ve zorluk seviyeleri açısından rastgele bir dağılım göstermektedir.

İstanbul C1+ ders kitabındaki metinlerin okunabilirlik düzeyleri hesaplanmış ve sonuçlara ilişkin bilgiler Tablo 3’te gösterilmiştir.

Tablo 3

İstanbul C1+ Ders Kitabındaki Metinlerin Okunabilirlik Durumları

\begin{tabular}{|c|c|c|c|c|c|c|c|c|}
\hline & Metin Adı & $\begin{array}{l}\text { Topla } \\
\text { m } \\
\text { Hece } \\
\text { Sayis1 }\end{array}$ & $\begin{array}{l}\text { Topla } \\
\text { m } \\
\text { Kelime } \\
\text { Sayis1 }\end{array}$ & $\begin{array}{l}\text { Topl } \\
\text { am } \\
\text { Cüml } \\
\text { e } \\
\text { Sayıs } \\
1\end{array}$ & $\begin{array}{l}\text { Ortalam } \\
\text { a Kelime } \\
\text { Uzunluğ } \\
\text { u }\end{array}$ & $\begin{array}{l}\text { Ortalam } \\
\text { a Cümle } \\
\text { Uzunluğ } \\
\text { u }\end{array}$ & $\begin{array}{l}\text { Okunabi } \\
\text { lirlik } \\
\text { Puan1 }\end{array}$ & Okunabilirlik Düzeyi \\
\hline $1 \mathrm{~A}$ & Saatin İcad 1 & 2079 & 757 & 50 & 2,7463 & 15,14 & 48,97 & Zor \\
\hline 1B & $\begin{array}{l}24 \text { Saat } \\
\text { Yetmiyorsa... }\end{array}$ & 2036 & 706 & 61 & 2,8838 & 11,57 & 52,78 & Orta Güçlükte \\
\hline $1 \mathrm{C}$ & $\begin{array}{l}\text { Ünlü Bilim } \\
\text { Adamlarının } \\
\text { Çocuklukları }\end{array}$ & 1765 & 622 & 51 & 2,8376 & 12,19 & 53,15 & Orta Güçlükte \\
\hline $2 \mathrm{~A}$ & Aşkın Kimyası & 1400 & 555 & 44 & 2,5225 & 12,61 & 64,57 & Orta Güçlükte \\
\hline 2B & $\begin{array}{l}\text { Ünlü Aşıklar ve Aşk } \\
\text { Mektupları }\end{array}$ & 1497 & 601 & 51 & 2,4908 & 11,78 & 68,02 & Orta Güçlükte \\
\hline $2 \mathrm{C}$ & Aşkın Sırrı & 2027 & 798 & 99 & 2,5401 & 11,78 & 66,04 & Orta Güçlükte \\
\hline $3 \mathrm{~A}$ & $\begin{array}{l}\text { Büyük İkramiyeyi } \\
\text { Kazanıp Sonra } \\
\text { Kaybedenler }\end{array}$ & 1576 & 534 & 43 & 2,9513 & 12,41 & 47,87 & Zor \\
\hline 3B & Satranç ve Tavla & 1200 & 472 & 32 & 2,5423 & 14,75 & 58,20 & Orta Güçlükte \\
\hline $3 \mathrm{C}$ & Elmas Gerdanlık & 2591 & 1004 & 112 & 2,5806 & 8,96 & 71,77 & Kolay \\
\hline $4 \mathrm{~A}$ & $\begin{array}{l}\text { Arzuhâlden } \\
\text { Dilekçeye }\end{array}$ & 556 & 183 & 14 & 3,0382 & 13,07 & 42,66 & Zor \\
\hline 4B & $\begin{array}{l}\text { İş Görüssmelerinde } \\
\text { İşverenler Nelere } \\
\text { Dikkat Eder? }\end{array}$ & 962 & 321 & 31 & 2,9968 & 10,35 & 51,42 & Orta Güçlükte \\
\hline $4 \mathrm{C}$ & $\begin{array}{l}\text { Fatih Sultan Mehmet } \\
\text { Mahkemede }\end{array}$ & 1080 & 422 & 26 & 2,5592 & 16,23 & 53,65 & Orta Güçlükte \\
\hline $5 \mathrm{~A}$ & Lumiere Kardeşler & 1302 & 449 & 38 & 2,2984 & 11,81 & 75,67 & Kolay \\
\hline $5 \mathrm{~B}$ & Susuz Yaz & 1797 & 790 & 108 & 2,2746 & 7,31 & 88,37 & Kolay \\
\hline
\end{tabular}




\begin{tabular}{|c|c|c|c|c|c|c|c|c|}
\hline $5 \mathrm{C}$ & $\begin{array}{l}\text { Yabancı Ülkelerde } \\
\text { Yayınlanan Türk } \\
\text { Dizileri }\end{array}$ & 1339 & 550 & 28 & 2,4345 & 19,64 & 49,76 & Zor \\
\hline $6 \mathrm{~A}$ & Bilge ve Bilgelik & 1585 & 607 & 63 & 2,6112 & 9,63 & 68,79 & Orta Güçlükte \\
\hline $6 \mathrm{~B}$ & Bilgi Teknolojisi & 1089 & 337 & 26 & 3,2314 & 12,96 & 35,24 & Zor \\
\hline $6 \mathrm{C}$ & $\begin{array}{l}\text { Bilgi Toplumu ve } \\
\text { Üniversiteler }\end{array}$ & 1994 & 703 & 44 & 2,8364 & 15,97 & 43,19 & Zor \\
\hline $7 \mathrm{~A}$ & Sanat Nedir? & 1182 & 438 & 43 & 2,6986 & 10,18 & 63,85 & Orta Güçlükte \\
\hline $7 \mathrm{~B}$ & Sanat Türleri & 1240 & 449 & 39 & 2,7616 & 11,51 & 57,84 & Orta Güçlükte \\
\hline $7 \mathrm{C}$ & $\begin{array}{l}\text { Türk Süsleme } \\
\text { Sanatları }\end{array}$ & 1539 & 576 & 54 & 2,6718 & 10,66 & 63,67 & Orta Güçlükte \\
\hline $8 \mathrm{~A}$ & Suç Nedir? & 1523 & 525 & 40 & 2,9009 & 13,12 & 48,04 & Zor \\
\hline $8 B$ & Adalet Nedir? & 1189 & 404 & 31 & 2,9430 & 13,03 & 23,82 & Çok Zor \\
\hline $8 \mathrm{C}$ & Esaretin Bedeli & 1594 & 604 & 83 & 2,6390 & 7,27 & 73,83 & Kolay \\
\hline $9 \mathrm{~A}$ & $\begin{array}{l}\text { Mizah Her Kapıyı } \\
\text { Açar }\end{array}$ & 2054 & 726 & 59 & 2,8292 & 12,30 & 53,06 & Orta Güçlükte \\
\hline $9 B$ & Mizah Türleri & 1010 & 389 & 35 & 2,5964 & 11,11 & 65,52 & Orta Güçlükte \\
\hline $9 \mathrm{C}$ & Hasan Kaçan & 388 & 158 & 15 & 2,4556 & 10,53 & 72,69 & Kolay \\
\hline $10 \mathrm{~A}$ & $\begin{array}{l}\text { Dünden Bugüne } \\
\text { "Para" }\end{array}$ & 1999 & 762 & 53 & 2,6233 & 14,37 & 55,93 & Orta Güçlükte \\
\hline 10B & $\begin{array}{l}\text { Türkiye'de } \\
\text { Enflasyonun Tarihsel } \\
\text { Gelişimi }\end{array}$ & 1433 & 514 & 26 & 2,7879 & 19,76 & 35,25 & Zor \\
\hline $10 \mathrm{C}$ & $\begin{array}{l}\text { Öğrenciler İçin } \\
\text { Tasarruf Yöntemleri }\end{array}$ & 1727 & 594 & 47 & 2,9074 & 12,63 & 49,06 & Zor \\
\hline $11 \mathrm{~A}$ & Dünyamız & 870 & 317 & 28 & 2,7444 & 11,32 & 59,03 & Orta Güçlükte \\
\hline $11 \mathrm{~B}$ & $\begin{array}{l}\text { Küresel Isınma } \\
\text { Nedir? }\end{array}$ & 856 & 294 & 21 & 2,9115 & 14 & 45,32 & Zor \\
\hline $11 \mathrm{C}$ & Dünya'dan Mars'a & 1160 & 459 & 27 & 2,5272 & 17 & 52,92 & Orta Güçlükte \\
\hline $12 \mathrm{~A}$ & $\begin{array}{l}\text { Gençlerin Medya } \\
\text { Tüketimi }\end{array}$ & 1475 & 503 & 36 & 2,9324 & 13,97 & 44,56 & Zor \\
\hline $12 B$ & $\begin{array}{l}\text { Mert'in İletişim } \\
\text { Serüveni }\end{array}$ & 1516 & 602 & 84 & 2,5182 & 7,16 & 78,98 & Kolay \\
\hline $12 \mathrm{C}$ & $\begin{array}{l}\text { İnternet ve Sosyal } \\
\text { Medya Bağımlılığ }\end{array}$ & 1391 & 485 & 43 & 2,8680 & 11,27 & 54,19 & Orta Güçlükte \\
\hline
\end{tabular}

İstanbul Yabancılar İçin Türkçe C1+ Ders Kitabı okuma metinleri okunabilirlik düzeyi açısından incelendiğinde karşımıza çıkan sonuçlar Tablo 1'de görülmektedir. Ders kitabında 12 bölümde toplam 36 okuma metni bulunmaktadır. Metinlerin ortalama sözcük uzunlukları 2,29 ile 3,23 arasında değișmektedir. Türkçenin ortalama sözcük uzunluğu 2,6 hecedir (Ateșman, 1997; Bezirci ve Y1lmaz, 2010). Buna göre kitapta yer alan 23 metin ortalamanın üzerindedir. 13 metin ise ortalama sözcük uzunluğu açısından ortalamanın altındadır. Metinlerin ortalama cümle uzunlukları ise 7,16 ile 19,76 arasındadır. Türkçenin ortalama cümle uzunluğu dikkate alındığında kitapta yer alan metinlerin 4 tanesi ortalamanın altında, 32 tanesi ortalamanın üstündedir.

Metinler okunabilirlik düzeyleri açısından incelendiğinde 6 metnin kolay, 18 metnin orta güçlükte, 11 metnin zor, 1 metnin ise çok zor olduğu görülmektedir. Metinlerin okunabilirlik puanları 23,82 ile 88,37 arasında değişmektedir. Okunabilirlik puanı azaldıkça metnin zorluk düzeyi artmaktadır. Buna göre metinler arasında en kolay olanı 88,37 güçlük düzeyi ile Susuz Yaz, en zor olanı ise 23,82 zorluk düzeyi ile Adalet Nedir? isimli metinlerdir. Metinler genel olarak incelendiğinde çoğunun öğrencinin anlayabileceği zorlukta olduğu görülmektedir. Ancak zorluk düzeyi en fazla olan Adalet Nedir? isimli metin seviyenin üzerindedir. Kitapta yer alan metinler kolaydan zora doğru bir sıralama takip etmemektedir. 
Eserin ilk metni okunabilirlik açısında zor düzeyde iken sondan bir önceki metin kolay düzeydedir. Üniteler ve metinler arasında zorluk düzeyleri açısından bir sıralama yoktur.

Tablo 4

İstanbul C1+ Ders Kitabı ve Yeni Hitit 3 Kitaplarının Okunabilirlik Düzeyleri Açısından Karşılaştırılması

\begin{tabular}{cll}
\hline Okunabilirlik Düzeyi & İstanbul C1+ & Yeni Hitit 3 \\
\hline Çok Kolay & - & - \\
Kolay & 6 & 4 \\
Orta Güçlükte & 18 & 10 \\
Zor & 11 & 17 \\
Çok Zor & 1 & 7 \\
\hline Toplam & 36 & 38 \\
\hline
\end{tabular}

İstanbul C1+ ve Yeni Hitit 3 kitaplarının her ikisi de 12 üniteden oluşmaktadır. İstanbul $\mathrm{C} 1+$ kitabında 36 metin yer alırken Yeni Hitit 3'te 38 metin yer almaktadır. İstanbul C1+ kitabının ortalama sözcük uzunluğu 2,29 ile 3,23 arasında değişmektedir. Buna karşın Yeni Hitit 3 ortalama uzunlukları 2,35 ile 3,16 arasında değişen sözcüklerden oluşmaktadır. Bu verilere göre Yeni Hitit 3 kitabı ortalama sözcük uzunluğu açısından daha uzun sözcüklere sahiptir.

İstanbul C1+ kitabındaki metinlerin ortalama cümle uzunlukları 7,16 ile 19,76 arasındadır. Yeni Hitit 3’te ise 5,36 ile 39,33 arasında değişmektedir. Buna göre Yeni Hitit 3 kitabı cümle uzunluğu açısından oldukça değişken bir yapıya sahiptir. Türkçenin ortalama cümle uzunluğunun epey üstünde cümle/cümleler barındırmaktadır. İstanbul $\mathrm{C} 1+$ kitabı ise uzunlukları açısından birbirine daha benzer yapıda cümlelere sahiptir.

Kitaplar okunabilirlik düzeyleri açısından incelendiklerinde ise İstanbul C1+ kitabında yer alan metinlerin 18 tanesinin orta güçlükte, 6 metnin kolay düzeyde, 11 metnin zor, 1 metnin çok zor düzeyde olduğu; Yeni Hitit 3 kitabında ise 4 metnin kolay düzeyde, 10 metnin orta düzeyde, 17 metnin zor ve 7 metnin çok zor düzeyde olduğu görülmektedir. İstanbul $\mathrm{C} 1+$ 'da 1 metin çok zor düzeydeyken Yeni Hitit 3'te 7 metin çok zor düzeydedir. Her iki kitaptaki metinlere okunabilirlik düzeyleri açısından bakıldığında İstanbul $\mathrm{C} 1+$ kitabında yer alan metinlerin orta düzeye daha yakın olduğu görülmektedir.

Kolaydan zora doğru sıralanıp sıralanmaması açısından incelendiğinde her iki kitapta da bu hususa dikkat edilmediği söylenebilir. Kitaplardaki metinler kolaylıklarına göre sıralanmamış, konularına/temalarına göre bir sıralamaya tabi tutulmuşlardır.

Tablo 5

Kitapların Okunabilirliklerine Yönelik t-testi Sonuçları

\begin{tabular}{lcccccc}
\hline & Kitap & $\mathrm{N}$ & Aritmetik Ortalama & $\begin{array}{c}\text { Standart } \\
\text { Sapma }\end{array}$ & $\mathrm{t}$ & $\mathrm{p}$ \\
\hline Ort. Sözcük Uzunluk & Yeni Hitit 3 & 38 & 2,82 &, 23036 & 2,061 &, 043 \\
& İstanbul C1+ & 36 & 2,71 &, 21637 & & \\
Ort. Cümle Uzunluk & Yeni Hitit 3 & 38 & 15,84 & 6,12632 & 2,990 &, 004 \\
& İstanbul C1+ & 36 & 12,48 & 2,92884 & & \\
Okunabilirlik Puanı & Yeni Hitit 3 & 38 & 44,12 & 20,77908 & $-3,048$ &, 003 \\
& İstanbul C1+ & 36 & 56,60 & 13,43999 & & \\
\hline
\end{tabular}


Ders kitaplarının ortalama sözcük uzunlukları arasındaki farka ait $\mathrm{t}$ değeri $(\mathrm{t}=2,061$, $\mathrm{p}<0.05$ ) anlamlı bulunmuştur. Bu sonuçtan hareketle Yeni Hitit 3'ün İstanbul C1+'e göre daha uzun sözcüklere sahip olduğu söylenebilir.

Ders kitaplarının ortalama cümle uzunlukları arasındaki farka ait $\mathrm{t}$ değeri de $(\mathrm{t}=2,990$, $\mathrm{p}<0.05$ ) anlamlı bulunmuştur. Bu sonuçtan hareketle Yeni Hitit 3'ün İstanbul C1+'e göre daha uzun cümlelere sahip olduğu söylenebilir.

Ders kitaplarının okunabilirlik puanları arasındaki farka ait $\mathrm{t}$ değeri $(\mathrm{t}=-3,048, \mathrm{p}<0.05)$ anlamlı bulunmuştur. Bu bulguya göre İstanbul $\mathrm{C} 1+$ 'in Yeni Hitit 3'e göre okunabilirlik puanlarının daha fazla olduğu söylenebilir. Buna göre İstanbul $\mathrm{C} 1+$ 'in okunabilirlik puan ortalamasının "orta güçlükte", Yeni Hitit 3'ün okunabilirlik puan ortalamasının "zor" olduğu anlaşılmaktadır.

\section{Sonuç ve Öneriler}

Okunabilirlik formülleri metinlerin dil yapısıyla ilgili bilgileri vermektedir. Ancak okunabilirlik düzeyleriyle metinler hakkında verilen fikirler belli orandadır. Bu nedenle sadece okunabilirlik düzeylerine bakarak metinlerin kolay veya zor olduklarına yönelik kesin kararlar vermek hatalı sonuçların ortaya çıkmasına neden olabilir. Bu çalışmada Yeni Hitit 3 ve İstanbul $\mathrm{C} 1+$ ders kitaplarındaki metinlerin okunabilirlik düzeyleri belirlenmiştir. Çalışmadan ortaya çıkan sonuçlara göre metinlerde öğrenci düzeylerine uygun metinlerin yanında seviyelerinin üstünde metinlerin de yer aldığını söylemek mümkündür.

Yeni Hitit 3 ders kitabında yer alan metinlere kelime uzunluğu açısından bakıldığında, 38 metinden 32 tanesinin ortalamanın üstünde olduğu söylenebilir. Kitapta yer alan 39,33 kelimelik uzunluğa sahip cümlelerin olduğu metinler öğrenciler için uygun olmayan metinlerdir. Yine aynı kitaptaki 35 metin, ortalama cümle uzunluğunun üstündedir. Yeni Hitit 3 ders kitabındaki metinler okunabilirlik düzeyleri açısından incelendiğinde 24 metnin zor ve çok zor seviyede olduğu, 10 tanesinin orta güçlükte ve 4 tanesinin ise kolay seviyede olduğu görülmektedir. 24 metnin zor ve çok zor seviyede olması kitaptaki metinlerin öğrenci seviyesinin üstünde zorluk düzeyinde olduğunu ortaya koymaktadır. Kitapta yer alan çok zor seviyesindeki 7 metnin ise öğrencinin seviyesinin çok üstünde olduğunu söylemek mümkündür. Ders kitaplarında, özellikle de yabancılara Türkçe öğretiminde kullanılan ders kitaplarında bulunan metinlerin sıralanışının kolaydan zora doğru olması beklenmektedir. Fakat Yeni Hitit 3 kitabında yer alan metinlerin kolaydan zora doğru bir sıralamaya göre dizilmediği görülmektedir. Kitabın bu yönüyle eksik olduğu söylenebilir.

İstanbul C1+ ders kitabında yer alan 36 metinden 23 tanesi Türkçenin ortalama sözcük uzunluğunun üstündedir. Yine aynı kitaptaki metinlerin 32 tanesi Türkçenin ortalama cümle uzunluğunun üstündedir. İstanbul $\mathrm{C} 1+$ kitabında yer alan metinlerin yarısının orta güçlükte, 6 metnin kolay, 12 metnin ise zor ve çok zor seviyesinde olduğu görülmektedir. Kitapta, okuma düzeyleri açısından genel olarak öğrenci seviyesine uygun metinler yer almaktadır. Ancak kitapta yer alan bir metin çok zor seviyesinde olduğu için öğrenci seviyesinin üzerindedir. İstanbul $\mathrm{C} 1+$ ders kitabındaki metinler de kolaydan zora doğru bir sıralama izlememektedir.

Çalışmadan ortaya çıkan sonuçlara göre aşağıdaki önerilerde bulunulmuştur:

Yabancılara Türkçe öğretiminde kullanılan ders kitaplarında bulunan metinler, öğrencilerin rahat bir şekilde okuyup anlayabileceği uzunlukta sözcüklerden oluşmalıdır. Metinlerde yer alan cümleler de öğrencilerin anlayabileceği uzunlukta olmalıdır. Öğrenci seviyesinin üstünde uzunluğa sahip cümleleri öğrencilerin anlaması beklenemez. Çok kısa cümleler veya çok uzun cümleler öğrenci seviyesine uygun değildir.

Kitaplarda yer alan metinler okunabilirlik düzeyleri açısından öğrenci seviyesine uygun olmalıdır. Seviyelerinin çok altında kolaylığa veya çok üstünde zorluğa sahip metinler, yabancılara Türkçe öğretiminin hedeflerine ulaşılmasının önüne geçecektir. Ayrıca çok kolay metinler öğrencilerin sıkılmalarına, zor metinler ise özgüvenlerini kaybederek derslerden soğumalarına neden olabilir. Bu nedenle kitaplara alınacak metinler öğrenci seviyesine uygunluk açısından değerlendirilmelidir. 
Türkçenin yabancı dil olarak öğretimi A1, A2, B1, B2 ve C1+ seviyelerinden oluşan 5 kurda yapılmaktadır ve her kur bir önceki kurdan daha zor bir yapıya sahiptir. Kurlar arasındaki kolaydan zora sıralamasına kurların içinde de uyulması gerekmektedir. Bir kurda yer alan her ünitenin bir öncekinden zor, ünitelerde yer alan her konunun da yine bir öncekine göre daha zor olmas1 gerekmektedir. Kitaplarda yer alan metinler, metinlerde yer alan cümle ve sözcükler de yine aynı şekilde kolaydan zora doğru bir sıralamaya tabi olmalıdır. Her metin bir öncekinden daha zor olmalıdır. Bu sıralamada Ateşman (1997) tarafindan verilen ortalama sözcük ve cümle uzunlukları dikkate alınabilir.

Yabancılara Türkçe öğretiminde kullanılan kitaplardan İstanbul C1+ kitabında ve Yeni Hitit 3 kitabında yer alan metinlerin okunabilirlik düzeyleri açısından incelendiği bu çalışma ile metinlerin güçlük düzeyleri ortaya çıkarılmıştır. Ders kitaplarını hazırlayanların ve bu alanda görev yapan öğretim elemanlarının metin seçiminde zorluk düzeylerini göz önünde bulundurmaları hem amaçlarına hem de hedeflerine ulaşmaları açısından etkili olacaktır.

\section{Kaynaklar}

Ateşman, E. (1997). Türkçede okunabilirliğin ölçülmesi. A.Ü. Tömer Dil Dergisi, 58, 171-174.

Bezirci, B. ve Yılmaz, A. E. (2010). Metinlerin okunabilirliğinin ölçülmesi üzerine bir yazılım kütüphanesi ve Türkçe için yeni bir okunabilirlik ölçütü. DEÜ Mühendislik Fakültesi Fen Bilimleri Dergisi, 12(3), 49-62.

Chall, J. S. (1988). The beginning years. eds. B. L. Zakalukand ve S. J. Samuels. (Yay. haz.). Readability: Its past, present, and future, içinde. Newark, DE: International Reading Association P.

Çetinkaya, G. (2010). Türkçe metinlerin okunabilirlik düzeylerinin tanımlanması ve sınıflandırılması (Yayımlanmamış doktora tezi). Ankara Üniversitesi Sosyal Bilimler Enstitüsü, Ankara.

Çetinkaya, G. ve Uzun, L. (2010). Türkçe ders kitaplarındaki metinlerin okunabilirlik özellikleri. H. Ülper (Yay. haz.), Türkçe Ders Kitabı Çözümlemeleri içinde (s. 141155). Ankara: Pegem Akademi Yayınları.

Güneş, F. (2000). Çocuk kitaplarında okunabilirlik ilkeleri. Yaşadıkça Eğitim, 67, 35-40.

Hızarc1, S. M. (2009). Illköğretim 6. sinıf yeni sosyal bilgiler ders kitaplarının okunabilirlik düzeylerinin incelenmesi (Yayımlanmamış yüksek lisans tezi). Gazi Üniversitesi Eğitim Bilimleri Enstitüsü, Ankara.

Solmaz, E. (2009). İlköğretim 4. ve 5. sinıf düzeylerindeki türkçe metinlerde cümle uzunluğu, kelime uzunluğu ve kelime hazinesinin okunabilirlik üzerine etkisi (Yayımlanmamış yüksek lisans tezi). Gazi Üniversitesi Eğitim Bilimleri Enstitüsü, Ankara.

Temur, T. (2003). Okunabilirlik (readability) kavramı. TÜBAR-XIII, 169-180.

Ülper, H. (2010). Okuma ve anlamlandırma becerilerinin kazandırılmast. Ankara: Nobel Yayınlar1.

Yıldırım, A. ve Şimşek, H. (2008). Sosyal bilimlerde nitel araştırma yöntemleri (6. Baskl). Ankara: Seçkin Yayıncılık.

Yılmaz, F. ve Temiz, Ç. (2014). Yabancılara Türkçe öğretiminde kullanılan ders kitaplarındaki metinlerin okunabilirlik durumları. IJLET, 2, 70-80.

\section{Extended Abstract}

\section{Introduction}

Text books are one of the most important and mostly used materials in Teaching Turkish to Foreigners as well as at every grade of education. For texts which are in text books that are basic materials in lessons, being applicable for the target audience is a very important issue. Reading of texts which are compatible with the grade can be beneficial and aims of Teaching Turkish to Foreigners will be achieved. When choosing a text for a textbook, there are different ways to determine if it is compatible with the grade and one of them is specifying readability degree of the text. In this study, it is aimed to determine readability degree of texts which are in 
Yeni Hitit 3 Yeni Hitit 3 and İstanbul C1+ used by many language centers for teaching Turkish to foreigners. Although there are many studies on readability of texts in literature, these studies are insufficient in the field of teaching Turkish to foreigners. Y1lmaz and Temiz (2014) made a study by analyzing texts which are in Hitit series in this field. However, in this study Hitit 3 and İstanbul $\mathrm{C} 1+$ will be compared in terms of readability. This study will contribute a lot to literature by comparing these two book series which are commonly used in teaching Turkish as a foreign language in terms of readability.

\section{Method}

Document analysis method is used in this study based on comparison of texts in text books which are used in teaching Turkish as a foreign language in terms of readability. Yeni Hitit 3 and İstanbul $\mathrm{C} 1+$ text books which are used in teaching Turkish to foreigners are chosen in the study. These books are chosen since they are commonly used and prepared with advanced Turkish. Syllable, word and sentence lengths are calculated by selecting prose texts in the text books by researches. Syllables are divided according to Turkish syllable dividing method. When counting number of words, numbers with space, symbols and words which are divided by hyphen and abbreviations are counted as words. Number of sentences are counted according to their division by punctuation. Accumulated data is analyzed by SPPS 17.0 program. When making analysis, free sampling t-test is used to determine if there is difference between two books. Digital data is analyzed by using Flesch formula which was adapted to Turkish by Ateşman (1997) and readability scores of texts are determined.

\section{Results and Discussion}

When considering length of sentences in the texts which are in Yeni Hitit 3 text book, 32 of 38 texts are above average. Again, in the same book, 35 texts are above average sentence length. When considering readability degree of texts in Yeni Hitit 3 text book, 24 texts are hard and very hard, 10 are intermediate and 4 are easy. Having 24 hard and very hard text means the texts in the book have difficulty level which is above grade of students. It can be said 7 very hard texts in the book are much above the grade of students. It is expected that in text books, especially in text books which are used for teaching Turkish to foreigners, texts should be sorted from easy to hard. However, it is seen that texts in Yeni Hitit 3 are not sorted from easy to hard. Book has some deficiencies from this aspect.

23 of 36 texts in Istanbul $\mathrm{C} 1+$ text book are longer than Turkish average word length. Again, in the same book, 32 of the texts are above Turkish average sentence length. It is seen that half of texts in İstanbul $\mathrm{C} 1+$ are intermediate, 6 are easy and 12 are hard and very hard. Generally, the book has texts which are compatible with grade of students in terms of readability degree. However, since one of the texts is very hard, it is above grade of the students. Again, texts in İstanbul $\mathrm{C} 1+$ text book are not sorted from easy to hard.

Difficulty level of the texts are revealed in this study in which texts in İstanbul $\mathrm{C} 1+$ and Yeni Hitit 3 books which are used in teaching Turkish to foreigners are analyzed according to their readability degree. If instructors who prepare the text books and work in this field consider difficulty level of texts when choosing them, achieving their aims and targets will be easier and more effective. According to results revealed by the study, it is possible to say that there are texts above grade of students as well as texts which are compatible with grade of students in the books. 